\title{
10 Exterior interiors: the urban living room and beyond
}

\section{Joanna Merwood-Salisbury \& Vanessa Coxhead}

Despite the best efforts of high modernist architects and urban designers to privilege openness and continuous space, to do away with enclosure altogether, the contemporary global city is as much an interior condition as an exterior one. Early manifestations of the 'urban interior' appeared in late-nineteenth-century America, when skyscraper architects designed elaborate lobbies mimicking and competing with the streets outside. In the post-war era the invention of new architectural technologies allowed these public-scaled interiors to extend beyond the boundaries of the city block. Air-conditioning, fluorescent lighting, the escalator and long-span structural systems made possible the vast interior spaces characteristic of our contemporary urban landscape: the shopping mall, the office complex and the airport terminal (Koolhaas, 1995, 2000). Intrigued by the possibility of these mega-scale interiors, late-modern architects and designers began to adopt strategies typically associated with urban design in their conceptualization of these spaces (Stickells, 2006; Rice, 2016). 1 At the same time, just as commercial interiors began to acquire the scale and form of the public street, huge swathes of exterior space came under the control of corporate entities or public-private groups such as Business Improvement Districts: organizations that employ almost domestic-scale housekeeping strategies, such as the installation of seating and lighting, in an attempt to render city streets safe and comfortable for middle-class consumers (Mallett, 1994).

Consequently it may be argued that conventional concepts of interiority and exteriority, public and private, are of little use in describing the formal, spatial and social character of the late-modern megalopolis. In this proposition, to suggest a strict division between urban and interior design has become as problematic as drawing a clear line between built form and landscape, between the city and nature. How might we approach the analysis and design of such a confusing territory when conventional design concepts, practices and tools are no longer sufficient? In considering this question, the recent formulation of 'urban interiors' shows much promise. Discussing her self-identification as an 'urban interiorist', the designer 
and educator Suzie Attiwill has written: 'I am interested in the conjunction of "urban and interior" in relation to the design of interiors and what a practice of interior design has to contribute to the contemporary city' (Attiwill, 2011: 13). Here the discipline of interior design is removed from its traditional, supplementary relationship to architecture, allowing interior design expertise to be applied in broader contexts. The possibility of opening up a speculative space between disciplines, of creating hybrid practices, has been fruitfully explored elsewhere: for example, the positioning of 'landscape urbanism' as a credible form of practice and area of study (Corner, 1999; Waldheim, 2006). While it is not possible to erase disciplinary boundaries altogether, they may be suspended in order to allow different types of knowledge and different ways of working to emerge. Inspired by the discourse of urban interiors, this essay explores the ways in which concepts of interiority have structured the design of urban space from the mid-1960s until today. Beginning with two seemingly oppositional models - the urban living room and the urban surface - it introduces a series of contemporary examples in which concepts of interiority continue to contribute to the creative and innovative design of urban space. Illustrating an urban interiorist approach to the design of city parks, squares, streets and left-over spaces, they rely on strategies of appropriation (involving site-specific reactivation and reprogramming) and scalar confrontation.

\section{The urban living room}

Emerging out of post-war critiques of modernist urbanism, the metaphor of the urban living room is based on two seemingly contradictory ideas: the desire to both recapture the spatial character and social potential of the densely populated pre-modern city square (which has a grandeur and scale associated with hierarchical public rituals and ceremonies) and to lend urban space something of the domestic (to make it personal, intimate and comfortable). This rhetorical inversion, in which the exteriors became imagined in interior terms, appeared in the 1960s in reaction to high modernist city planning. For Le Corbusier, Mies van der Rohe and Ludwig Hilberseimer the dominant model of urban space was a continuous ground, a flat plane extending in all directions and forming an endless uninterrupted field on which pristine object-buildings stood. To cover these vast distances, high-speed automotive travel was privileged above pedestrian walkways. Applied wholesale to large areas of new or rebuilt development in the post-war years, this strategy was critiqued for its alienating effect. In an effort to solve this problem, writers and practitioners sought potential solutions in historical models. The critic Jane Jacobs famously praised the narrow nineteenth-century streets of Greenwich Village in New York City as a positive alternative to the wind-swept plazas dividing tower blocks in new housing developments (Jacobs, 1961). Architect and historian Colin Rowe went back even further in time to renaissance and baroque city planning. In his book Collage City, Rowe used the courtyard of the sixteenth century Uffizi Palace in Florence 
as an example of what he called an inverted figure-ground plan, an outside space surrounded by walls on all sides and inhabited as a sort of public interior (Rowe, 1978). For both Jacobs and Rowe these historical urban interiors promoted a civilized sociability and were vital to the performance of citizenship. Influenced by these writers, architects and urban designers began to experiment with inward-looking urban spaces designed to foster human interaction.

The work of sociologist William $\mathrm{H}$. Whyte proved hugely influential in popularizing the urban living room idea. ${ }^{2}$ During the 1960s he analyzed a number of the so-called pocket parks in New York City (Whyte, 1980). Using time-lapse photography he studied patterns of movement and occupation in order to extrapolate the principles of successful small-park design. His primary critique of his subjects was that many were designed primarily for visual appeal, or as elements within a larger urban composition, with little thought as to how people would inhabit them. For Whyte, effective pocket parks - like walled gardens, their ancient predecessors - embodied key qualities of interiority: they had plenty of seating and pronounced edges. These edges might not be walls - they could be plants, screens or changes in level - but they offered a similar feeling of containment and security, providing the occupants with a sense of belonging while at the same time preserving their visual connection to the surrounding city. Paley Park, in mid-town Manhattan, is often cited as the archetypal example of Whyte's design principles. Designed by landscape architects Zion and Breen in 1967, this miniature park is surrounded on three sides by high-rise buildings. One enters by ascending a flight of steps. At the top a grid of honey locust trees shades a cobblestoned plaza on which simple metal chairs encourage passers-by to pause and sit. The rear of the space is a high waterfall, with two ivy-covered slabs on either side. The sound of falling water muffles traffic noise, providing an aural boundary between the park and the street. Whyte particularly emphasized the importance of moveable seating to the social function, allowing people to alter the environment to their liking, to literally 'make room' for themselves, increasing their sense of control and belonging. 


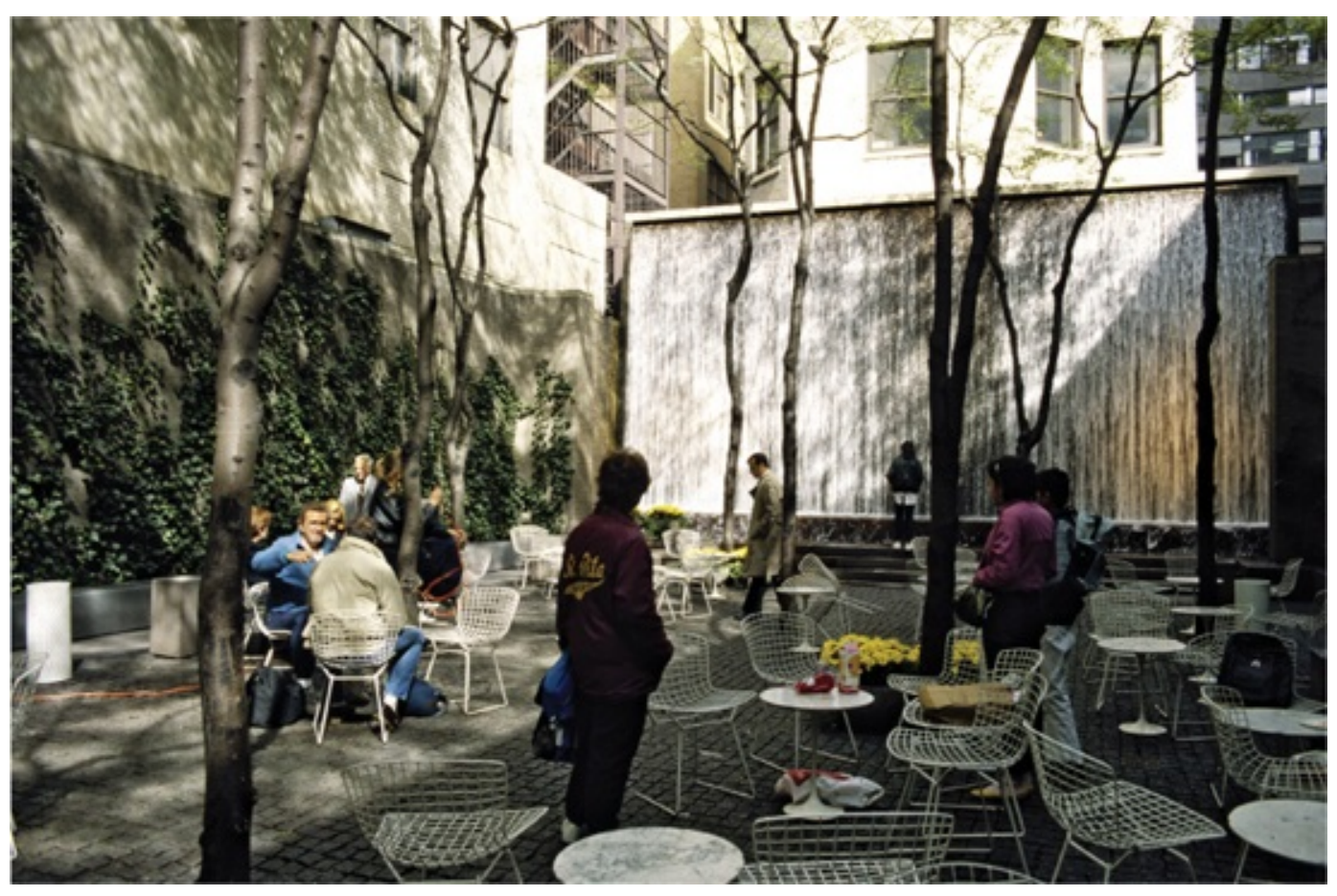

Figure 10.1

Paley Park, Zion \& Breen Architects, New York City, 1967. ART on FILE

In the late-twentieth-century the belief in the profoundly social function of urban space spread beyond corporate plazas to encompass much larger areas of the city, not just dedicated parks. Beginning in Europe, the urban designer Jah Gehl led a movement to reclaim city streets for pedestrians (Gehl, 2004). While Gehl usually works in collaboration with city authorities, others have taken a more bottom-up approach to the creation of new versions of the urban living room. The work of Rebar, a San Francisco art and design collective, typifies an approach often referred to as 'tactical urbanism'. Sometimes described as 'hacking the city', tactical urbanism uses temporary, low-cost and scalable design elements to activate underutilized outdoor spaces for community use (Lydon and Garcia, 2015: 73). Central to the success of the movement is that it can be implemented quickly, with the temporality of interior design rather than urban design. Like squatters taking over an abandoned building, in 2005 members of Rebar installed some artificial turf, a bench and a tree in a downtown parking space, feeding the meter to guarantee access to the spot. They called the result a 'parklet'. The project led to a larger movement in which parking spaces were transformed into temporary, car-sized parks, usable by the hour, all over San Francisco and in other cities. In 2010 Rebar expanded this idea, creating Walket, a modular system of slatted wooden benches, leaners, planters and bike racks designed to reclaim the parking lane for pedestrian use. With domestic scale mix-and-match pieces that can be quickly and easily combined and recombined, the system extends the sidewalk, providing places to sit, relax and socialize.

While these projects provide the means to activate streetscapes quickly and inexpensively, without the need for large-scale capital investment, the same general approach has been 
successfully adopted by civic entities in several cities. Beginning in 2008 the New York City Department of Transportation closed two of Broadway's four lanes between Herald Square and Times Square and installed a series of ad hoc pedestrian plazas made from green gravel glued to the road surface, furnished with plastic planters and lawn chairs (Sadik-Khan, 2015). The project attempted to solve the conflict between huge crowds and fast-moving cars by reducing traffic and offering tired tourists a place to sit. Set up for a trial period, the temporary plazas served as full-scale tests whose effects could be measured and modified. Snøhetta is now realizing the Times Square portion of the project in permanent form, replacing the lawn chairs with elegant granite benches. Complementing the glowing LED facades of surrounding buildings, the two-toned custom-paved ground surface is embedded with nickel-sized steel discs, activating the horizontal plane by capturing and scattering reflected light. A visual fold in the continuous ground surface, the benches provide pedestrians an opportunity to stop and admire their spectacular surroundings.

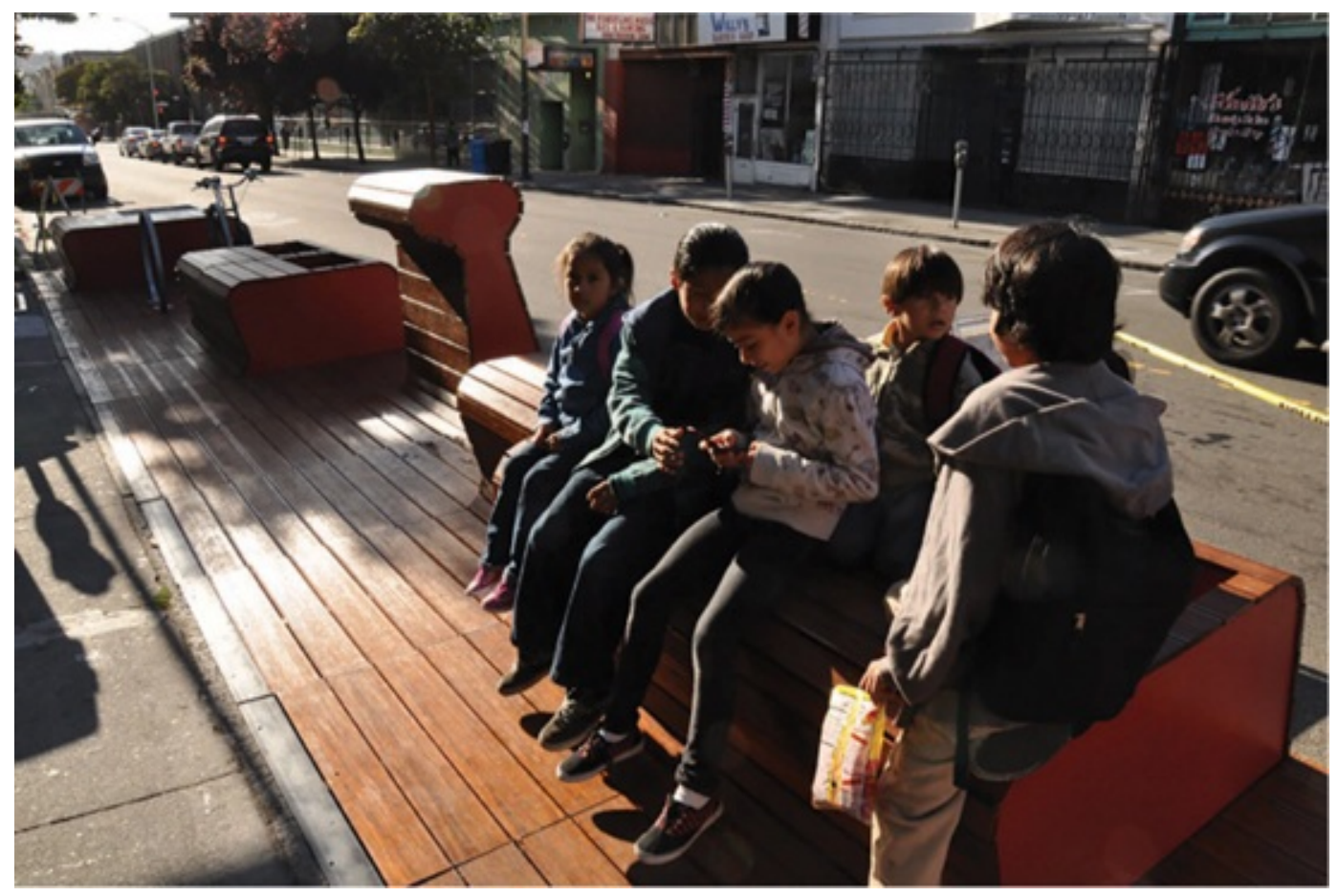

Figure 10.2

Walklet, Rebar, San Francisco, ongoing; first installed May 2010 @ Rebar 


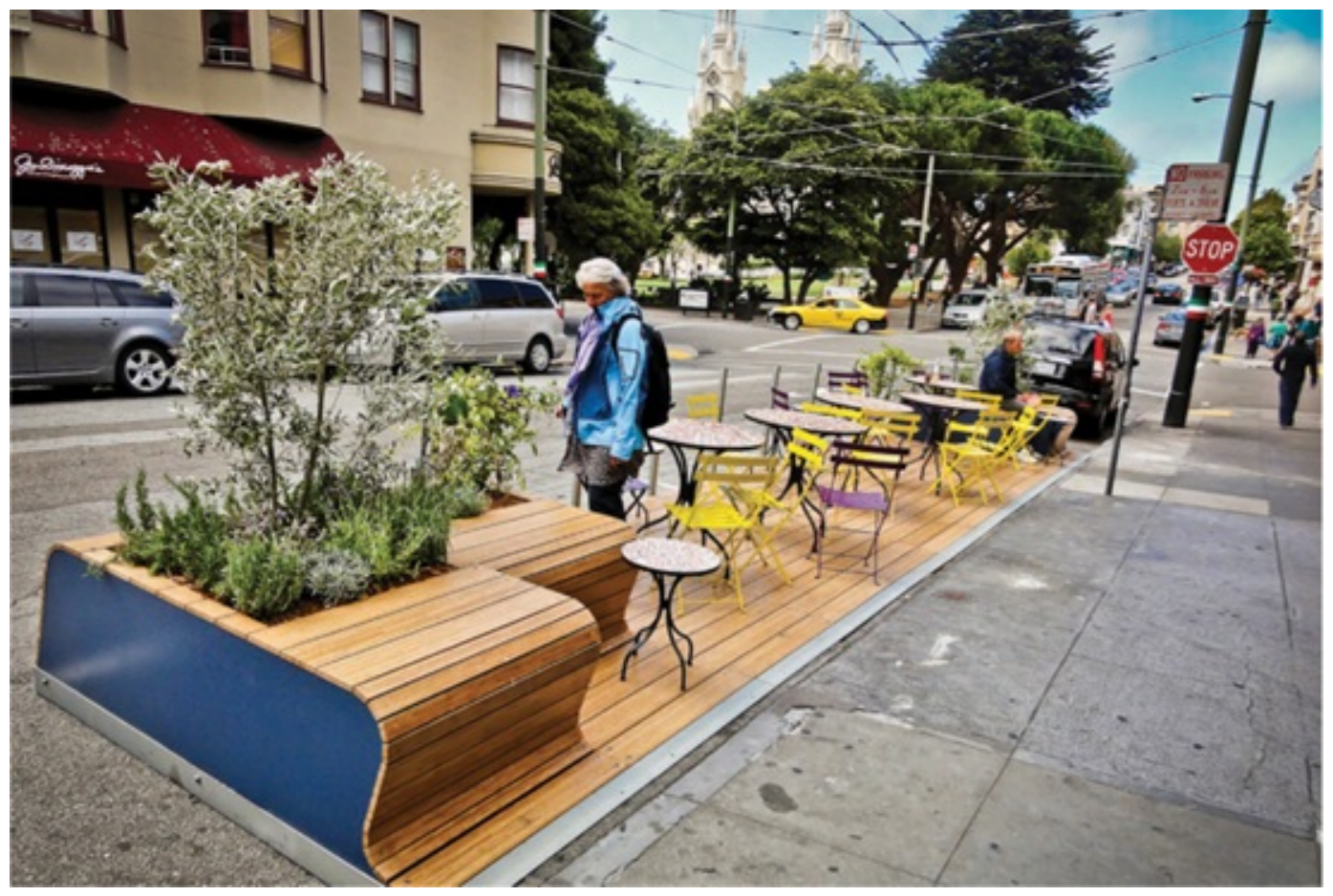

Figure 10.3

Walklet, Rebar, San Francisco, ongoing; first installed May 2010 ○ Rebar

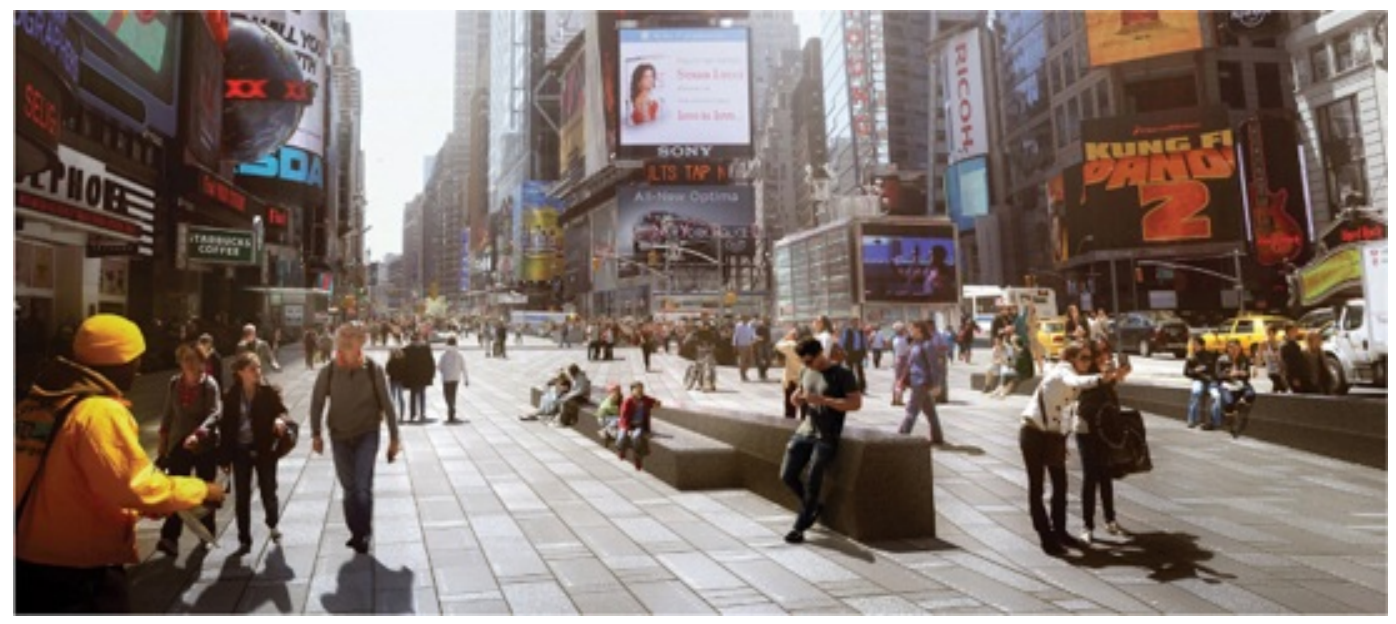

Figure 10.4

Visualization of Times Square Reconstruction, Snøhetta, New York City, 2016. ๑ Snøhetta and MIR

\section{The urban surface}

The Snøhetta project points towards a more recent model of urban place-making in which concepts of interiority are at play. This is the idea of the 'urban surface', which first appeared in the 1990s in reaction to what was seen as the overly prescriptive agenda of the urban living room. In one sense it may be seen as a revival of the modernist urban plane, with similar aims. But, as Alex Wall has suggested, the emphasis here is not on fixed functional-zones, as in early twentieth century city planning, but on multiple functions coexisting on a single surface and 
the promotion of dynamic flows of activity across it (Wall, 1999). The motivation behind this approach is to increase social capacity. Rather than dictating use, open and extensive urban platforms are created on which unexpected events might occur. Geographers Don Mitchell and Lynne Staeheli phrase it this way: 'The ideal form for public space is one that allows for a range of activities and for the appearance of a range of identities, but the way that this is managed is left open or unresolved' (Mitchell and Staeheli, 2007: 120). The creation of the latemodern version of the urban surface is aided by new technologies; in particular, computer software that allows designers to create non-Euclidean forms and complex curves. Exploiting the form-making ability of this software, projects featuring ground surfaces that fold into walls, which in turn become seating and ceilings, have become almost a cliché.

At first it might seem that the urban surface model is intrinsically anti-interior, certainly to the concepts of enclosure and privacy with which it is so often associated. However, more recent versions begin to borrow from the interior design tradition. The surface in question has a thickness: it folds and warps, providing corners and pockets for intimate inhabitation. The success of the model depends on the coexistence of multiple scales and types of activity. The surface must allow for roads and buildings, but also for the human body, the private encounter, in order for its full potential to be realized. For example, Avi Laiser and Dana Hirsch Laiser's 'the REAL estate', in Bat Yam, Israel (2008), features a continuous concrete 'blanket' wall in which biomorphic wooden niches are cut out, forming small private spaces within the surface of the larger public landscape.

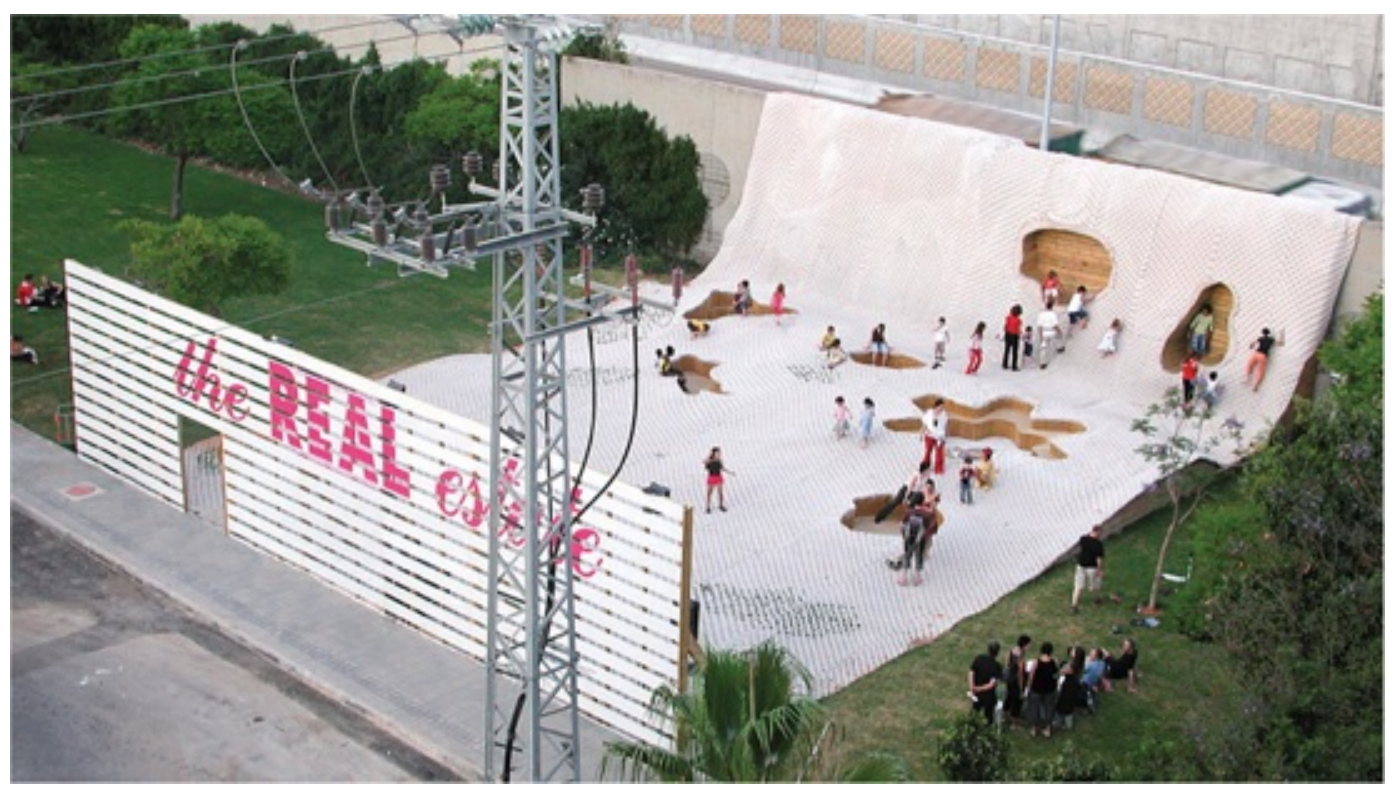

Figure 10.5

The REAL estate, AL/Arch, Bat Yam, Israel, 2012. (c) Avi Laiser 


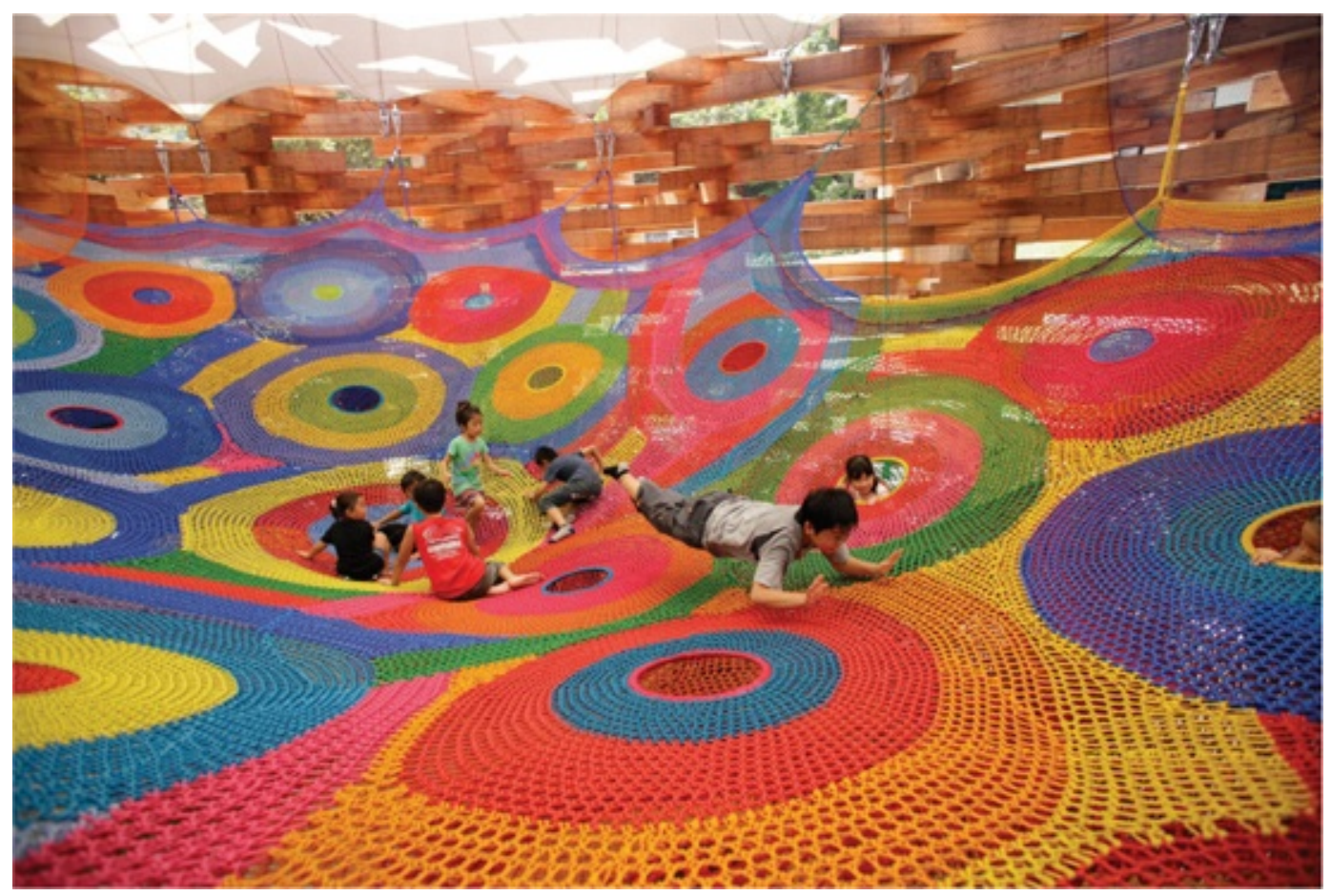

Figure 10.6

Knitted Wonder Space II, Toshiko Horiuchi MacAdam with Interplay Design \& Manufacturing, Inc. (net design \& construction) and Takaharu \& Yui Tezuka, Tezuka Architects (project design), Hakone Open Air Museum, Hakone, Japan, 2009. ๑ Masaki Koizumi

The reintroduction of the scale of the body brings us back to arguments supporting the urban living room, but at the same time it opens up another possibility: the application to exterior contexts of pliable, soft materials traditionally associated with interior spaces, such as curtains, wallpaper and carpets, which may incorporate vivid colour, texture and decorative effects. Referencing traditional feminine crafts, the artist Toshiko Horiuchi MacAdam's colourful knitted play structures explore the potential of textiles to become dynamic and three-dimensional, extending their scale and scope beyond the tactile to the tectonic.

Stadtlounge (2005), a plaza in St. Gallen, Switzerland, designed by Carlos Martinez Architekten in collaboration with artist Pipilotti Rist, is an evocative expression of a similar idea. The designers reactivate a previously underused space into a sort of 'city lounge', as the name implies, by literally rolling out the red carpet. The application of a continuous surface of red granulated rubber across pedestrian, recreation and rest areas brings cohesion to an area of irregular and unconnected voids, slowing down movement and tempting pedestrians to stop and touch their surroundings. The thickness, texture and pattern of the rubber is emphasized by the three-dimensional forms that emerge from under the surface: tables, benches, planters, a water fountain, even cars, are swathed in firehouse red. In this way the city fabric (made literal) is softer and more welcoming. Exploiting the semiotic associations of carpet, in contrast with typical plaza surfaces of asphalt or stone, the soft texture provides comfort. It has the 
capacity to receive impressions, for the wear and tear of habitual use to be made evident on its surface; the marks of human inhabitation are not seen as undesirable, but celebrated.

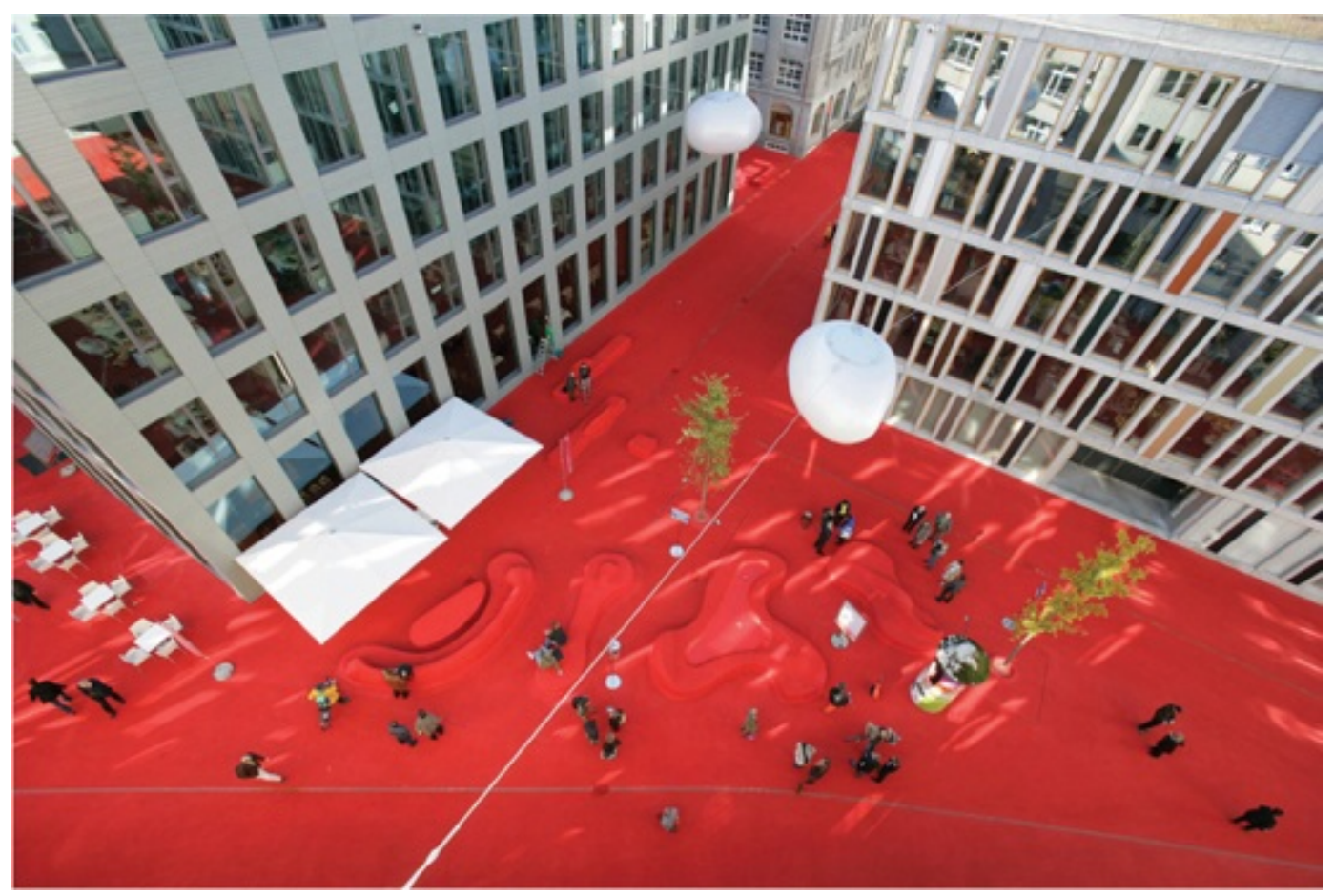

Figure 10.7

Stadtlounge, Carlos Martinez Architekten and Pipilotti Rist, St Gallen, Switzerland, 2005. (c) Marc Wetli and Hannes Thalmann 


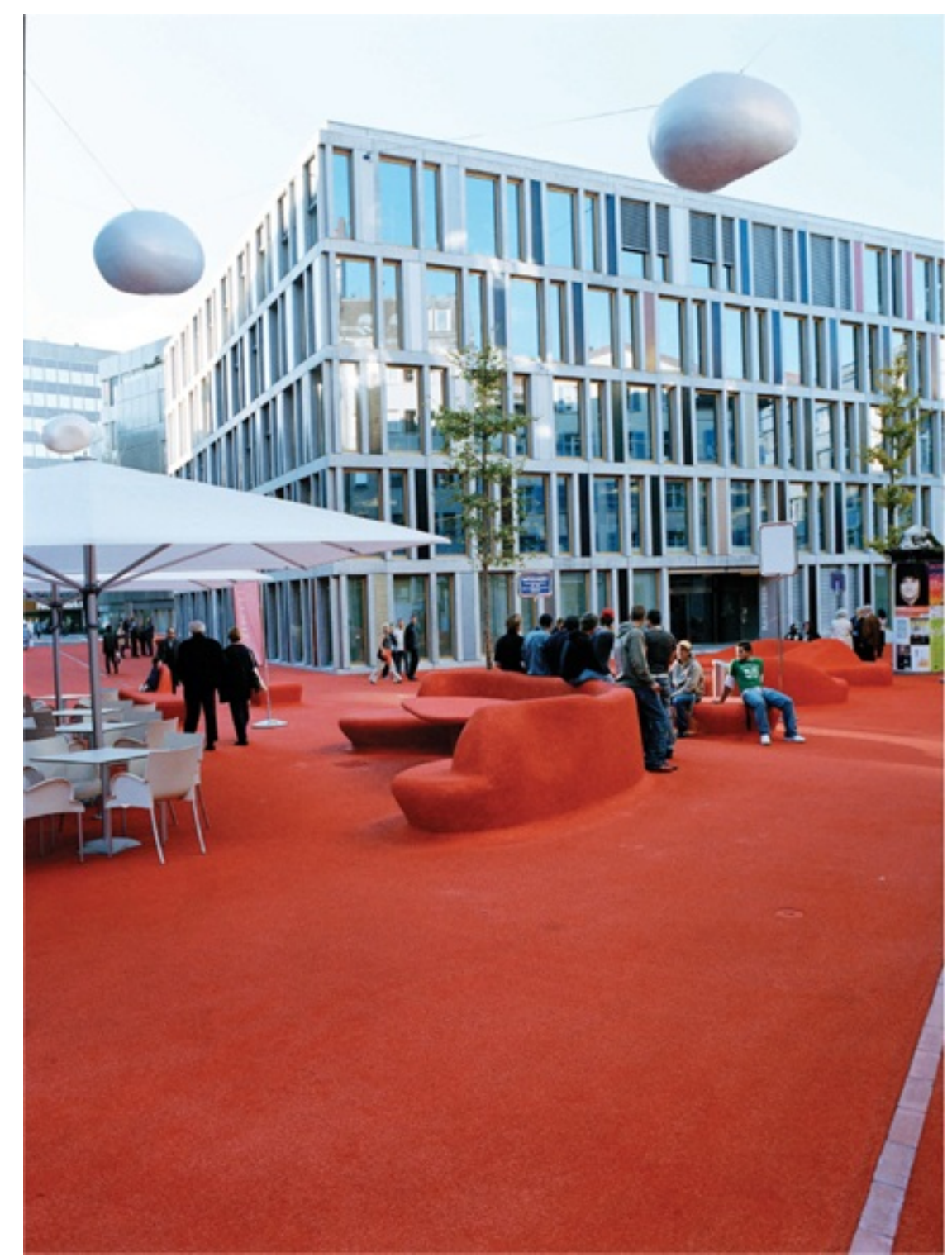

Figure 10.8

Stadtlounge, Carlos Martinez Architekten and Pipilotti Rist, St Gallen, Switzerland, 2005. ๑ Marc Wetli and Hannes Thalmann

\section{Appropriation}

The projects described so far concentrate on the provision of comfortable, human-scaled environments within often-inhospitable cityscapes. With their focus on seating and shading devices they present a homogenous, safe and predictable vision of urban public space. In order to reveal a wider range of design propositions, any discussion of contemporary urban interiors must also feature work with a more pointed intent, what Rochus Hinkel has described as 'speculative installations and interactions in the public sphere' (Hinkel 2011: 81). This approach shares similarities with the practice of tactical urbanism described earlier. But rather than restricting itself to typical 'urban living room' functions - sitting, eating, socializing in small 
groups - other forms of interior activity are brought outside and, in the process, transformed by being made public and accessible. This is not an open-ended concept of urban functionality where anything is possible. Instead it is a highly prescribed and specific use of public space, often intended to preserve what scholars and community activists call 'social sustainability', which refers to 'maintaining and enhancing the diverse histories, values and relationships of contemporary populations' (Low, Taplin and Scheld, 2005: 5). When realized successfully, such projects position urban interiorism as a collective and site-specific form of social space production.

Dance-O-Mat is a coin-operated dance floor first installed at various sites in Christchurch, New Zealand, in 2012. Following two damaging earthquakes, hundreds of buildings were demolished and many city blocks reduced to rubble-strewn empty lots, creating a devastating impact on civic morale. In response the ironically named collective Gap Filler produced a moveable outdoor dance floor and sound system made up of a series of banal interior fixtures: a washing machine, a disco ball and plastic flags. Set against the backdrop of a radically broken city, the well-used project produced moments of humour, playfulness and joy. The creators and guardians of the Dance-O-Mat discuss the importance of community acceptance to the success of the project. Such interventions require more than the placement of objects in space; they also require a well-tuned and empathetic understanding of what is needed in a particular place at a particular time.

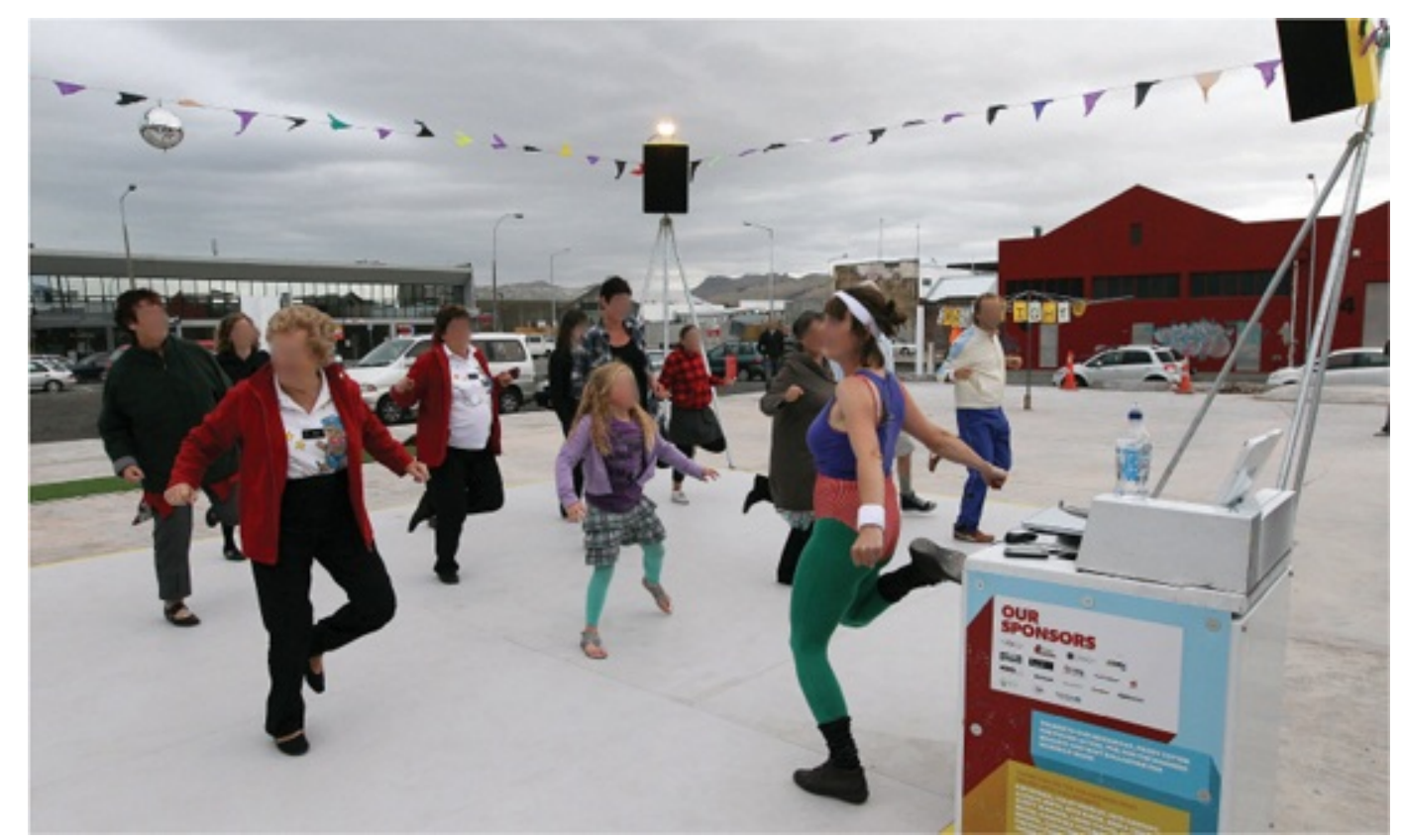

Figure 10.9

Dance-O-Mat, Gap Filler, Christchurch, NZ, ongoing; first installed 2012. ๑ Fairfax Media NZ/The Press

In a similar way, the work of the English art-architecture collective Assemble focuses on the ability of design to effect social transformation. Questioning normative modes of design 
practice and shifting towards a hands-on, collaborative working method, the collective is concerned with the way in which even simple, temporary constructions can act as catalysts for community building. For example, The Cineroleum (2010) on London's busy Clerkenwell Road transforms the forecourt of a derelict petrol station into a pop-up cinema. The cinema is formed by the unity of three disparate elements: the concrete and steel structure of the existing petrol station, a bank of tiered seats and an extravagant curtain of silvery drapery. This billowing reflective curtain softens the concrete structure, offering both shelter and a sense of theatricality to the otherwise banal site. Here the rich and ornate elements of cinema architecture are recreated in industrial, reclaimed or donated materials such as scaffolding and roofing membrane, with careful attention to handmade details. The project is a celebration of the shared escapism of cinema-going: when the curtain falls, viewers are transported far from the grimy site outside into a fantastic interior world.

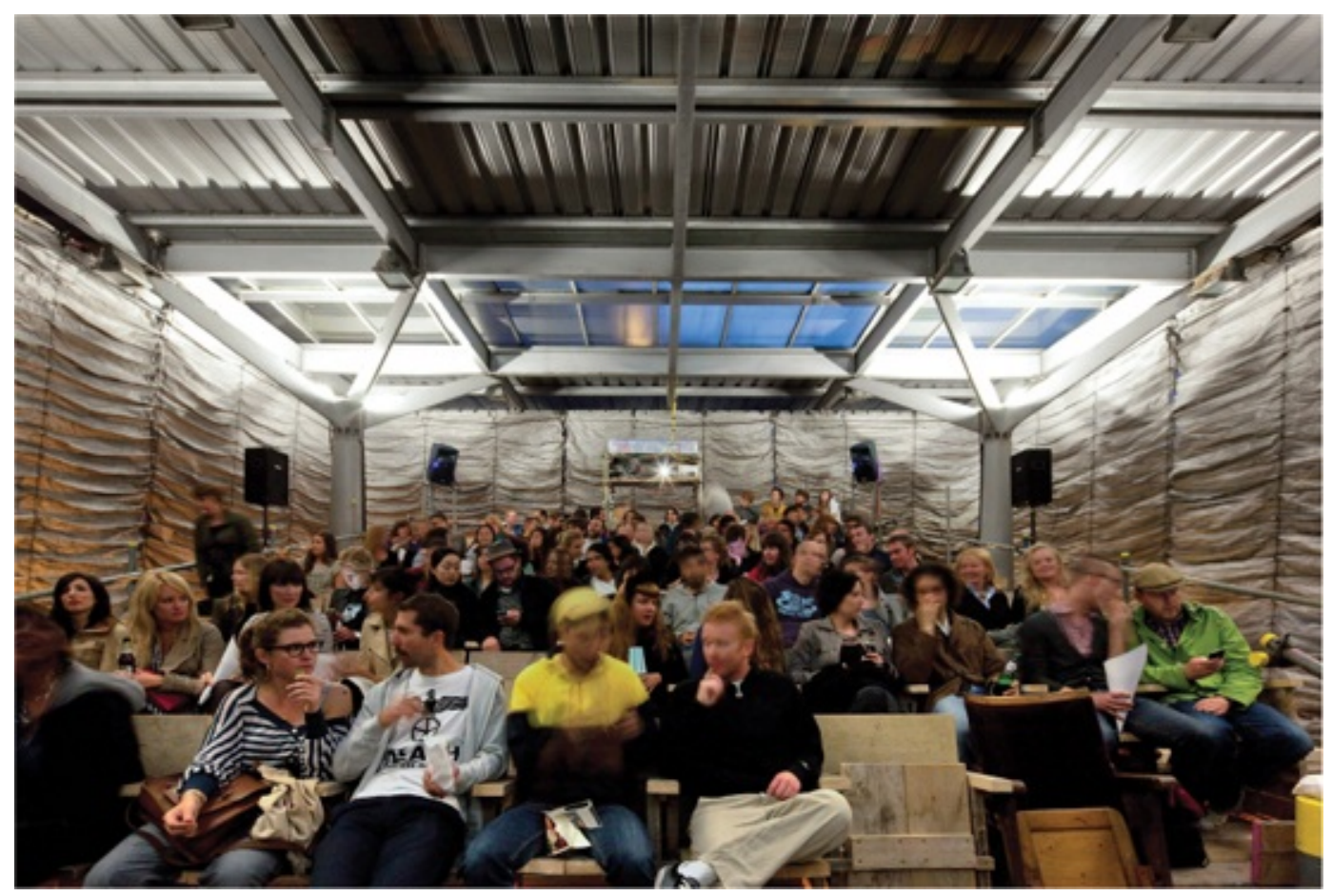

Figure 10.10

The Cineroleum, Assemble, London, 2010. ㄷ Morley Von Sternberg 


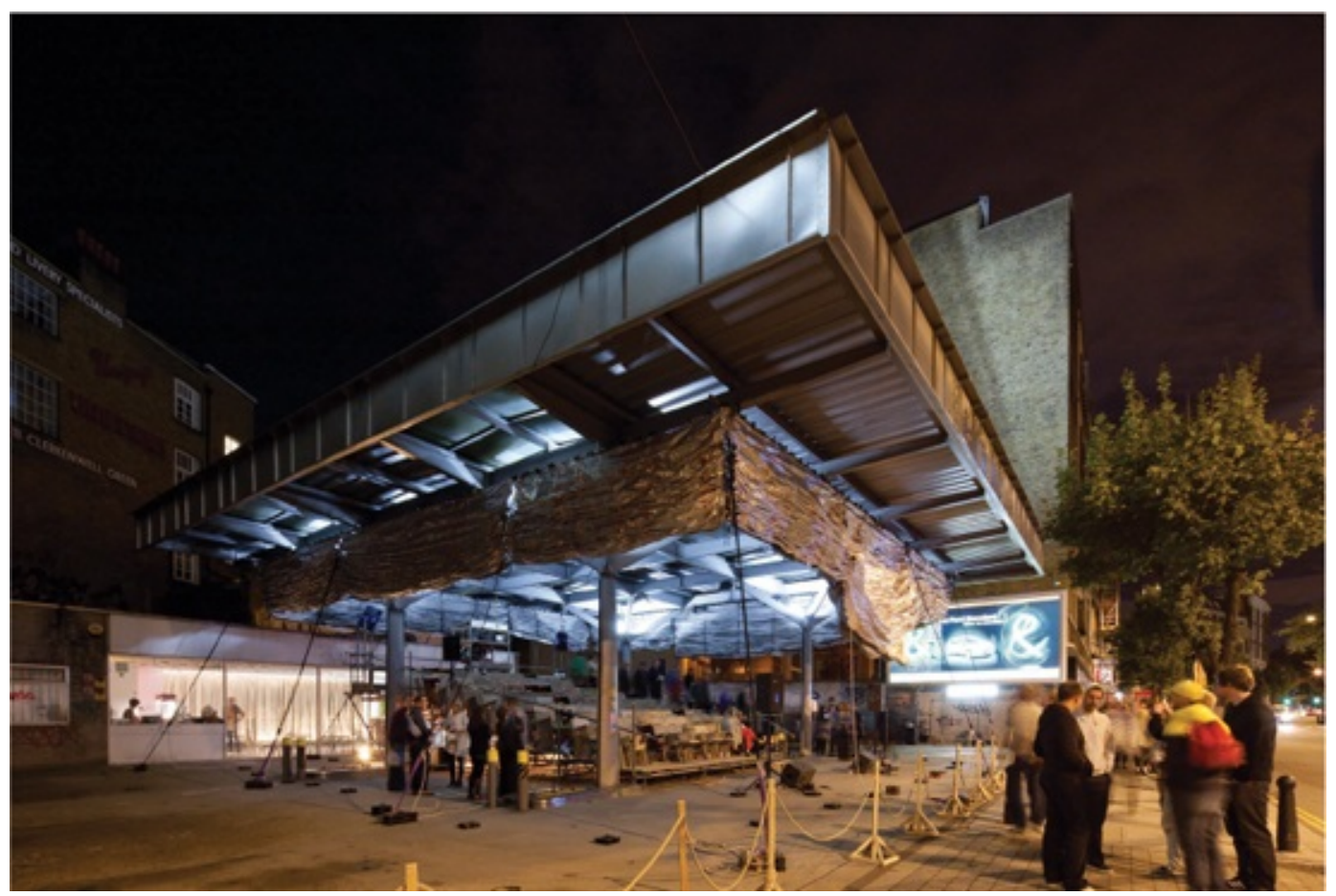

Figure 10.11

The Cineroleum, Assemble, London, 2010. ㄷ Morley Von Sternberg

\section{Scalar confrontation}

Describing the condition of late-modern architecture and urban design, the architect Rem Koolhaas identified something he called, or the 'Problem of the Large' (Koolhaas, 1995). The space of the city, he said, has become so impossibly vast and complex that traditional design tools and strategies are no longer sufficient to organize it or give it meaning. An unexpectedly simple interiorist approach to this dilemma is to hold firm to the power of the small, the quiet and the private within this metropolitan morass. The final category of urban interior to be discussed here is best termed 'scalar confrontation'. Bringing the scale, form and materials of furniture or domestic rooms into direct confrontation with the urban realm, with little or no threshold or transition, these projects emphasize continual and sometimes uncomfortable exchanges across the public and private divide, turning the sociability of one-to-one interaction into a political gesture. Transportability is often a feature, so as to activate different spaces at different times. This is sometimes expressed via mechanistic forms, with the elements of construction revealed. Hinkel calls such projects 'micro-architectures... small-scale interventions, which are minor in their spatial appearance, less dominant than large-scale buildings or infrastructures. These micro-architectures would not greatly change the aesthetic of a space, but would expand its potential use and allow for appropriations' (Hinkel 2011: 95).

The emphasis on amplifying social exchange is central to the work of Yoshiharu Tsukamoto and Momoyo Kaijima, partners in Tokyo-based Atelier Bow-Wow. Aaron Betsky has 
described their work as 'rearranging the ordinary' (Betsky, 2006: 97). For example, White Limousine Yatai (2003), which takes the traditional Japanese 'yatai', or street-side food cart, and stretches it from its typical 1.5 metre length to 10 metres, following the model of the stretch limousine. In doing so the small-scale charm of the traditional cart is extended to the scale of a banquet, encouraging the strangers seated together to interact over a meal..

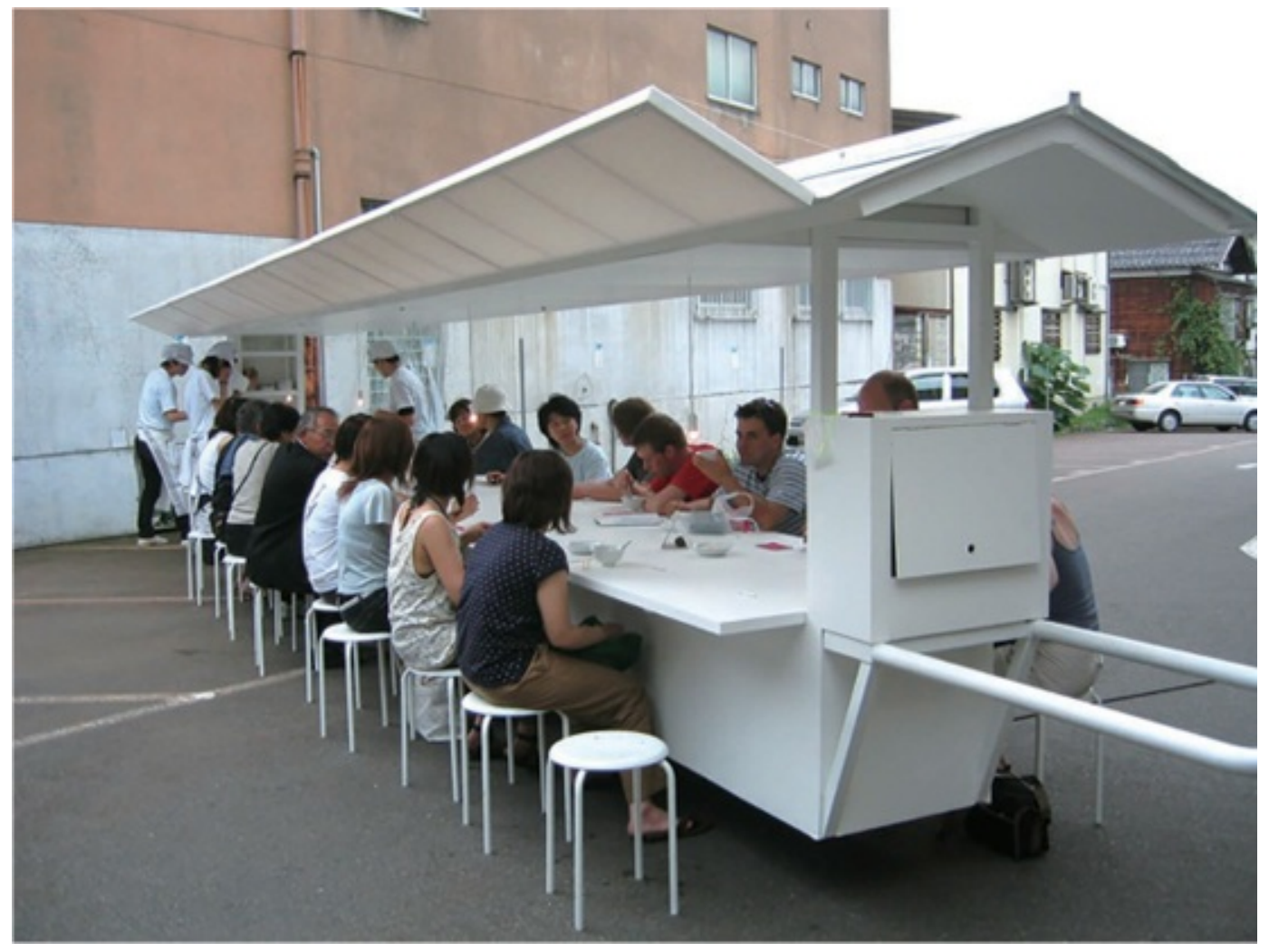

Figure 10.12

White Limousine Yatai, Atelier Bow-Wow, Echigo Tsumaari Art Triennale, Niigata, Japan, 2003. (C) Atelier Bow-Wow

The architect Colin Fournier and the artist Marysia Lewandowska's Open Cinema is another powerful example of this approach. Produced for the first time in 2012 as a temporary installation in Guimarães, Portugal, it has been re-presented in Lisbon (2013) and in Hong Kong (2016). The project is a free public cinema, made small and intimate within a large civic location, bringing strangers together at the scale of the domestic television. Though varied in its detail, each edition is based on the same basic design principle: spectators wanting to go in are required to manoeuvre their bodies, bending down underneath the curved exterior structure, entering via one of 16 downward-pointing nozzles into circular holes in the installation's underbelly. Once inside, the spectator's torso is immersed in a cinematic black box, a cool, dark and acoustically sealed cocoon lined with soft materials (cork or upholstery).

While most viewers choose to leave their feet planted firmly on the ground, the temptation to climb inside, to sit or lie within the structure, is apparent. In contrast to the usual cinemagoing experience - where the transition between outside and inside, the real world and the 
filmic environment, is drawn out through a series of intermediary thresholds - visitors to the Open Cinema exist simultaneously inside and outside, in both real and virtual space. Their lower bodies revealed, made public, the inhabitants are at the same time anonymous because their faces are invisible.

Taken together, these projects challenge our understanding of public space in the contemporary city and the possibilities for its design. To be public has traditionally meant to be expansive and exposed, open and transparent, to allow for the kind of massed crowds associated with pre-modern squares and marketplaces. As the literature on urbanism reveals, these kinds of spaces were at one time vital to the formation of public opinion, to the expression of political ideas and to the performance of citizenship. But in the twenty-first century, as digital media have become our primary form of communication, public space is no longer covalent with the public sphere. At the same time the existence of a singular 'public' has also been called into question. Scholars have identified the existence of so-called counter publics (groups often alienated from mainstream forms of representation) and alternative public spheres, self-created places in which a variety of identities are expressed and acknowledged (Crawford, 1995). The economic forces and architectural mechanisms that created the modern megalopolis, a place in which concepts of inside and outside begin to lose their meaning, also provide an opportunity for designers to engage with these multiple publics, to understand urban space in new ways, and to make unprecedented interventions. As the projects shown here illustrate, the deployment of interior concepts of temporality, scale, form and materials greatly enlarges what is possible within the urban realm.

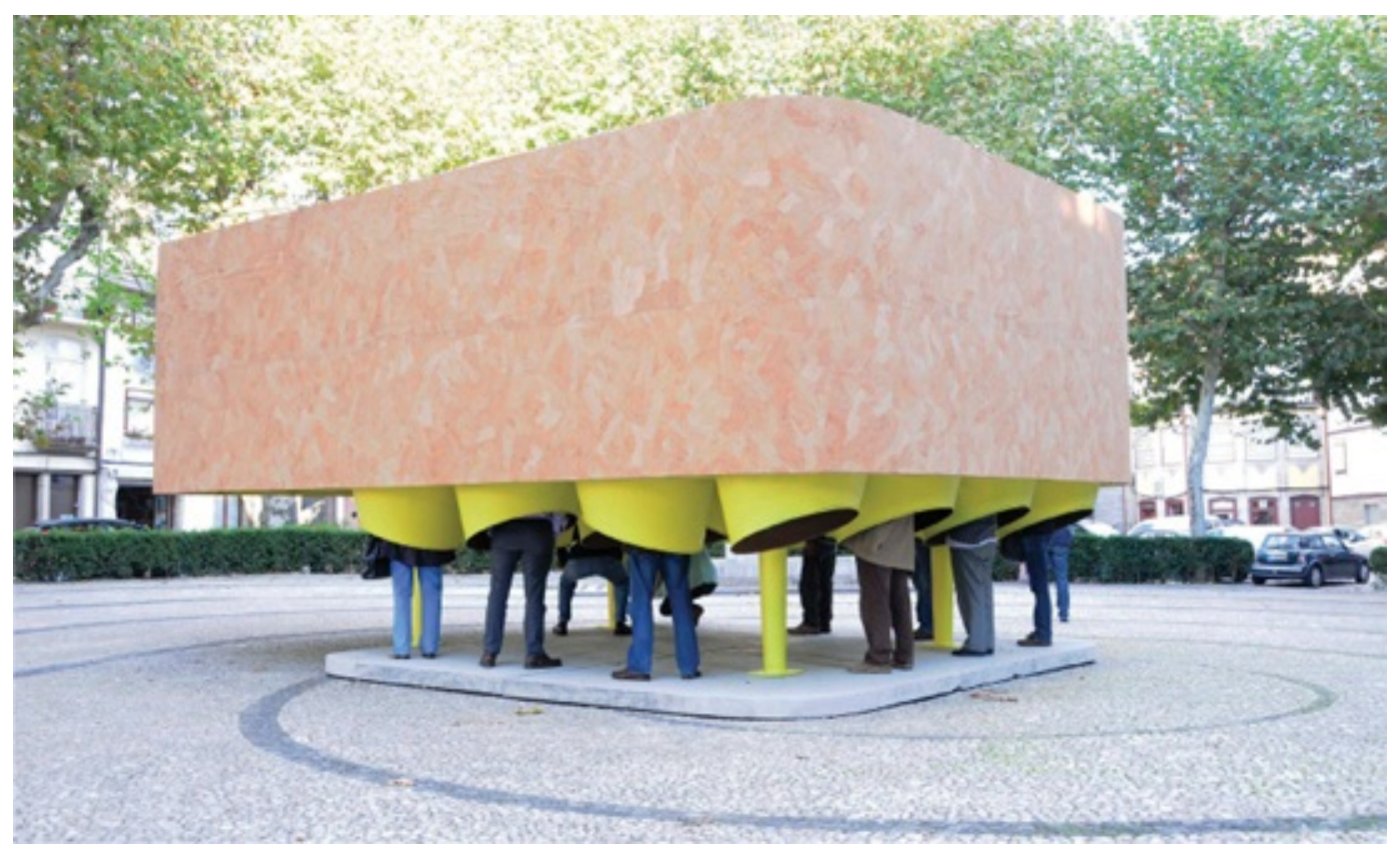

Figure 10.13

Open Cinema I, Colin Fournier and Marysia Lewandowska, Guimarães, Portugal, 2012. ๔ Colin Fournier and Marysia Lewandowska 


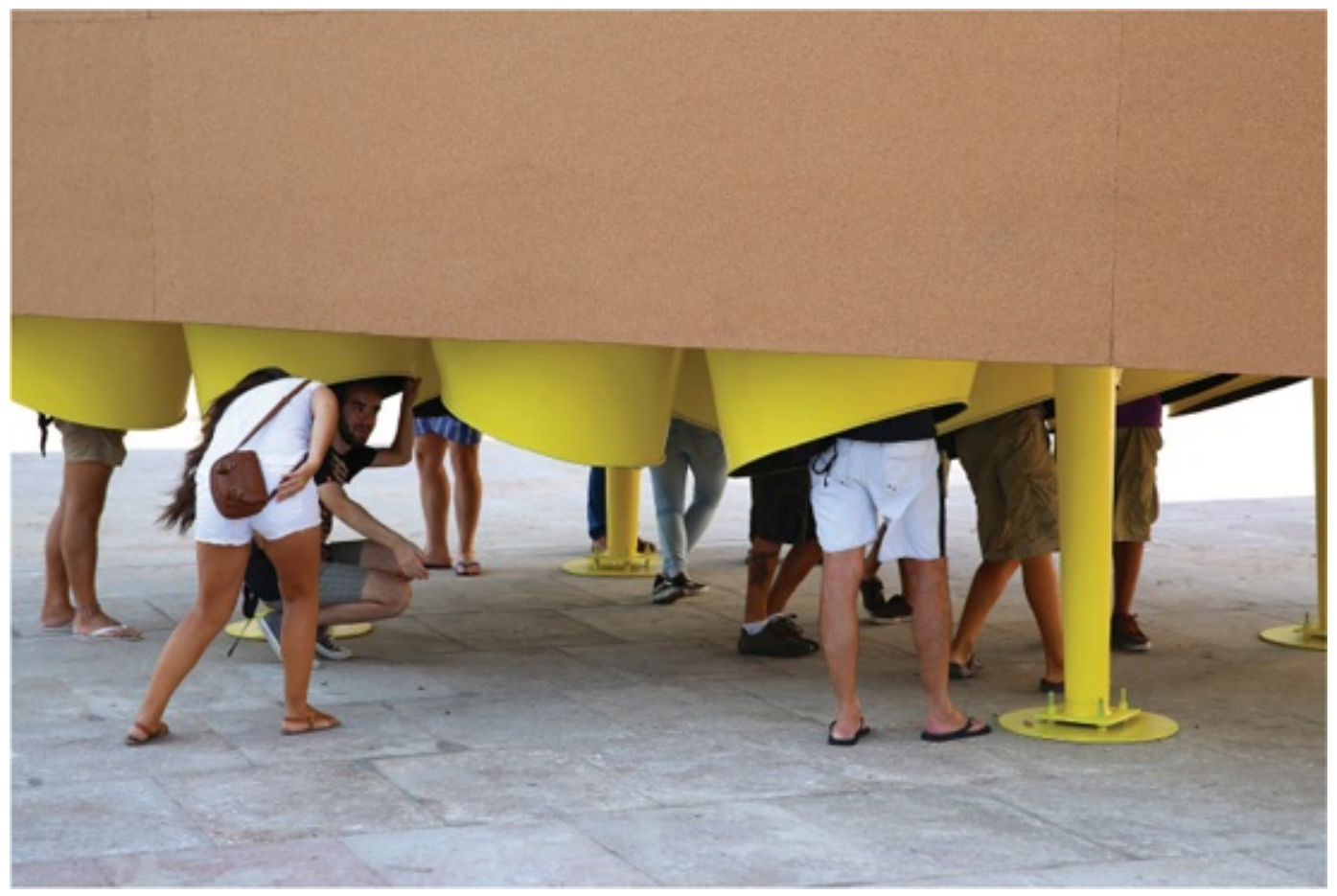

Figure 10.14

Open Cinema II, Colin Fournier and Marysia Lewandowska, Guimarães, Portugal, 2013. ๑ Colin Fournier and Marysia Lewandowska

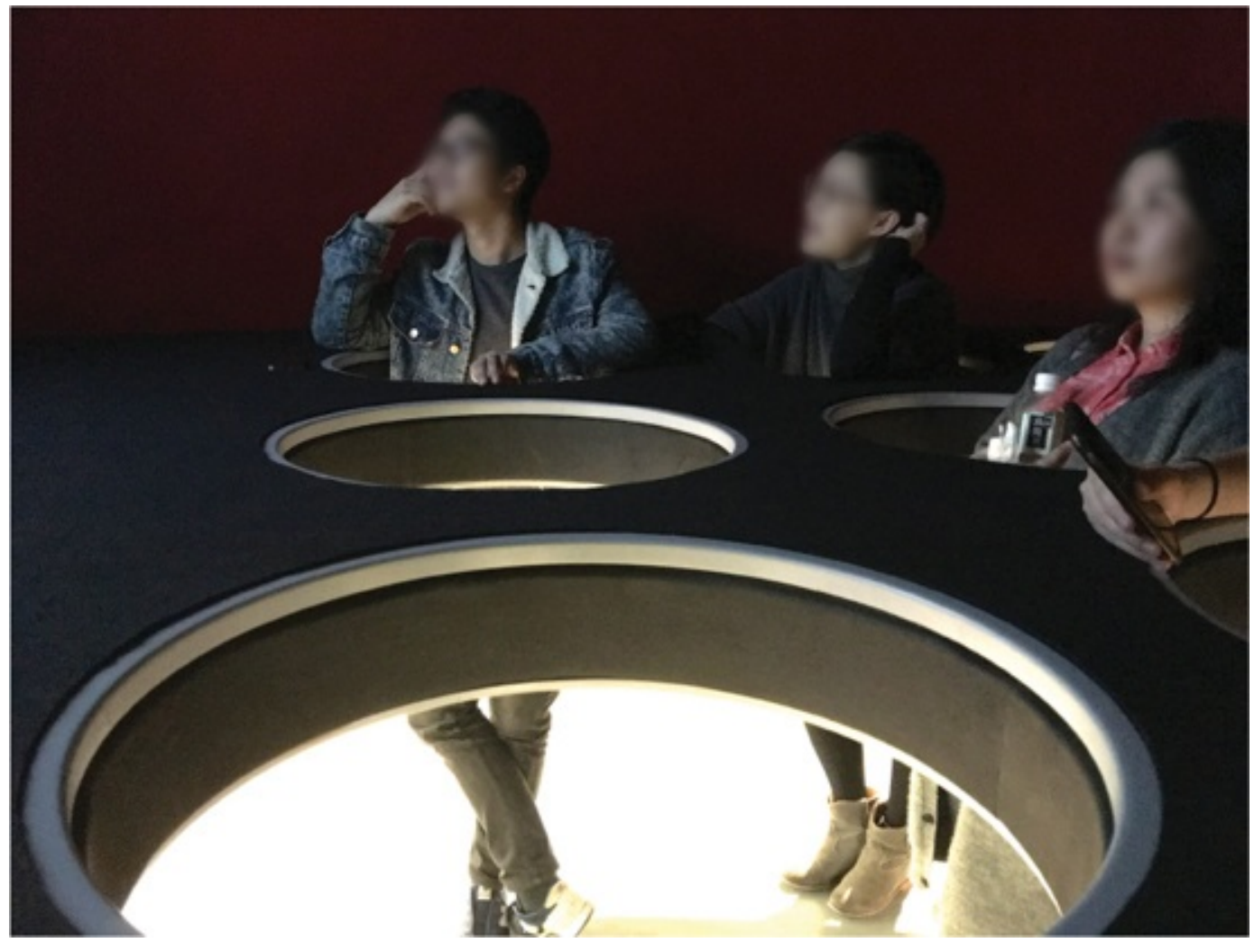

Figure 10.15

Open Cinema III, Colin Fournier and Marysia Lewandowska, Hong Kong, 2016. ๑ Colin Fournier and Marysia Lewandowska 


\section{Notes}

01 Charles Rice and Lee Stickells have both discussed the adoption of the metaphor of urbanism in the design of large-scale interior spaces, beginning with the work of American architect John Portman in the 1960s, through to the present day.

02 Whyte went on to found the Project for Public Spaces, which continues to research and publish on this topic. See, for example, Project for Public Spaces Inc. (1984) Managing Downtown Public Spaces, Chicago: Planners Press/American Planning Association. 